\title{
Computers and the liberal arts: Challenge to psychology
}

\author{
EDWARD A. DOMBER and JAMES W. MILLS \\ Drew University, Madison, New Jersey
}

\begin{abstract}
Three years ago Drew University began a campus-wide effort to integrate microcomputers into courses across the entire liberal arts curriculum. This paper summarizes the results of 14 studies that have assessed student and faculty responses to this effort, and concludes by suggesting some implications of these studies for psychologists involved in the design and evaluation of similar programs.
\end{abstract}

In the fall of 1984, Drew University began a campuswide initiative to integrate microcomputers into courses across the entire liberal arts curriculum. Since that time, each entering freshman has been issued a microcomputer with supporting software. During the first year of the program, faculty members and most administrative offices were supplied with similar packages, 80 microcomputers were placed in public work stations throughout the campus, and the Computer Center staff was expanded. Training sessions for faculty and students have been offered throughout the $21 / 2$ years of the program.

At Drew, members of the psychology department have been centrally involved in instigating, planning, administering, and evaluating this effort. As other colleges and universities move toward similar computer-intensive environments, it is likely that psychologists at these institutions will be important parts of these efforts. In this paper, we summarize some highlights of our research and experience by focusing on some implications of our work for others who may become involved in similar projects. Unlike most of the other papers in this session, we concern ourselves not so much with teaching and research applications in psychology per se, but rather with implications for psychology's part in implementing educational applications of computers across a campus.

To date, we have conducted about 14 separate studies assessing student uses, attitudes, and proficiencies prior to, during, and after the freshman year. We have also investigated faculty uses, attitudes, and proficiencies; compared faculty users and nonusers; evaluated student and faculty training; and assessed specific educational applications. Because of the amount of data, we limit this report to a few overall trends illustrated by specific findings. We organize these in the form of seven challenges for psychologists.

\section{THE CHALLENGES}

1. Find ways to convert general positive attitudes about the value of microcomputers in education into beliefs that

Address reprint requests to Edward A. Domber, Psychology Department, Drew University, Madison, NJ 07940. microcomputers will benefit individuals in specific ways. Both faculty and students speak much more favorably about computers and computing when they refer to computers in general than when referring to their own use of computers. For example, students and faculty strongly endorse such statements as "computers are a constructive addition to liberal arts education" and disagree with such statements as "computers are only relevant in math and science." Yet students are much less enthusiastic when rating the value of specific computer exercises for themselves, or when responding to personal attitude items, such as "computers will allow me to learn more in less time." Furthermore, actual time spent on learning and using the computer is less than might be expected given the enthusiasm expressed in many attitudinal measures. In addition, only $15 \%$ of faculty believe that computers have made them better teachers. Indeed, both students and faculty have taken a rather matter-of-fact attitude about a computer-intensive campus; students believe in the value of computers, but have not gone out of their way to learn applications that are not required, and faculty who express the same general attitude have not done much to provide new and innovative applications to the students.

Clearly, both students and faculty are enthusiastic about the potential of computers as educational tools, but they believe that for themselves, this potential is as yet unrealized. What can psychologists do to reduce the gap between perceived potential and immediate experience?

2. Understand the determinants of attitudes toward computers and computing. Although attitudes toward computers and computing are very favorable among our students and faculty, there are wide variations in attitude that interest us. What determined those attitudes? Does the way computers are presented, the nature of the software, or the length of training determine attitudes? What might we do to foster more favorable attitudes toward computers and their use?

Initially, our research identified no correlates of attitudes toward computing. Gender, prior ownership, use in high school, ethnic status, self-rated proficiency, and satisfaction with training were all unrelated to responses on the attitudinal items in our surveys. We did determine, 
however, that attitudes at the beginning of the freshman year correlated with attitudes at the end of the first semester. That is, students who came to college with favorable attitudes toward computing still had favorable attitudes after receiving their own computers, going through training, and using computers for a semester. Similarly, those arriving with less favorable attitudes had less favorable attitudes at the end of the semester.

In addition, measures of efficacy were correlated with attitudes. Students at the beginning of the semester who viewed themselves as likely to learn and use computers had more favorable attitudes toward computing at the end of the semester.

If we wish to foster favorable attitudes toward computing, we need to reach students very early, since their attitudes tend to persist regardless of their experience with computers. It also appears that fostering high efficacy expectations about one's ability to deal with computers will result in more favorable attitudes. At Drew, for example, the 1-h summer introduction to computers was changed from a lesson in computing, in which we tried to teach the students as much as possible, to an orientation, in which the goal was one of providing the students with a successful experience in computing. As psychologists, we should explore the extent to which facilitating the development of a sense of efficacy will foster more favorable attitudes toward computing. Furthermore, we can explore means of developing such efficacy in potential users.

3. Develop effective training methods and procedures. Research documented the widespread dissatisfaction with training on the part of the students and identified specific areas of difficulty for the faculty. One member of the research team who had taught college classes for over 25 years noted a large difference in the way his second, as opposed to his first, computer class was received. He was teaching the electronic spreadsheet and quickly discovered that teaching computer use is not like teaching other subjects. Three years of experience teaching freshman word processing has yielded much useful information on how to handle this task.

Our research and experience suggest several questions of interest to psychologists: What is the best way to train faculty, staff, and students in computer use? What particular problems does teaching the computer present? Is there a particular order in which various skills should be taught? Should classes for faculty be taught by computer center staff or regular faculty?

Particular attention needs to be paid to the teacherstudent relationship in computer classes, especially when a faculty member is teaching peers, or when students are teaching faculty. Our experience indicates that considerable time is saved and more is learned when the class members stay together, do not experiment independently, do not practice a function until it is demonstrated, and realize that mistakes are inevitable. For some faculty, this approach, while efficient, was more authoritarian than they preferred. Furthermore, many faculty are unaccus- tomed to computers and are uncomfortable finding themselves lost and confused. In many classes, some faculty sit and stare at a blank screen rather than ask for help. What can psychologists do to make training more efficient and comfortable for faculty, students, and staff?

\section{Expand student and faculty views of computer appli-} cations. Current faculty and student use is both encouraging and discouraging. For example, the impact of computers on students' lives, measured in terms of time, is quite extensive: students are currently using their microcomputers almost $1.5 \mathrm{~h}$ per day on the average. On the other hand, most of this time is spent on one type of application (i.e., word processing). The time spent on other applications, such as programming, data analysis, simulation, or CAI, is not nearly as large: 6-12 min per day on the average. Other measures of student use confirm this finding. In addition, students learn a given computer application only if it is required in the context of a course.

Notably, the data on faculty are similar. Although there are subgroups of faculty members interested in exploring additional uses for the computer, most of them see it as a word processor only. Although three fourths of the faculty reported using the microcomputers in their courses, most reported little or moderate use, almost all of which was word processing. Because faculty have not found or developed other computer applications for their courses, the data on student use are hardly surprising.

How can we enable students and faculty to gain an expanded view of the computer? How can faculty be helped to explore the teaching possibilities of computers? How can students learn to see the computer's possibilities aside from writing and editing papers, and playing electronic games? We have hired a software librarian and a faculty coordinator and funded software acquisition; we have provided student programmers; we have made training opportunities available to students and faculty. These direct attempts to address this issue have not, to date, had significant impact.

5. Measure the effectiveness of computers in curricula. The possibilities offered by use of the computer as a teaching tool, particularly those offered by interactive programming, have excited many faculty. The computer can give individual attention, can respond to statements made by the student, can display infinite patience, and can give immediate feedback. A well-developed interactive program can provide a learning experience unlike any other.

Drew University students were only moderately favorable in their attitudes toward computer exercises. In some instances, they were far less enthusiastic than were the instructors. The students reported their conviction that the computer helped them learn and indicated an interest in the exercises, but they evidenced very little excitement about this new teaching method.

How useful are such learning experiences for the college student? Do they increase learning or enhance motivation? Are they better or worse than lectures, texts, or 
audiovisual presentations? Under what circumstances or for what types of material would instruction by computer be more or less effective than other means? When the computer is an effective teaching tool, what properties of computing make it so: immediate feedback, patience, individualized instruction, motivation-enhancement? Although there is some evaluative data on some disciplines within the liberal arts, such as psychology, many of these questions have only begun to be investigated. The usefulness of the computer in teaching will be aided by research that answers these and related questions.

6. Develop incentives and other means for encouraging curricular applications of computers. Although most Drew faculty members make use of word processing, there is wide variability in the extent to which they have explored other computer functions or the instructional possibilities of the computer. One barrier to expanded use of the computer by faculty is lack of time. Faculty are extremely busy, and time is a precious resource; consequently, faculty members need some incentive if they are to devote their scarce time to learning how to use computers. Release time, special stipends, and credit for software development toward promotion and tenure are a few incentives. What can psychologists do to help identify and develop others? Can psychologists help evaluate the effectiveness of each of these incentives? What does the psychologist teach us about other ways of increasing computer use by faculty?

7. Search for predictors of attitudes, proficiency, use, and satisfaction among different subgroups of students and faculty. To date very few relationships among these variables have been found. In general, all students, male or female, minority or white, science-oriented or inexperienced, academically talented or not, have responded in the same (generally positive) way. The few exceptions to this are in some cases trivial (e.g., natural science, social science, and humanities students make somewhat different use of computers in their courses). The best predictor of student proficiency is extent of prior computer use. In other cases relationships among variables may be more informative. For example, students ask help from fellow students and are reluctant to ask help of faculty, but faculty are reluctant to ask help of either students or fellow faculty; male students generally rate themselves more proficient in all forms of computer use than do females. Why?

We need further research to explore the relationships we have found and to uncover others. Knowing what distinguishes faculty and student users and nonusers, identifying weaknesses and strengths of particular subgroups, and distinguishing patterns of use are important, so that future programs can be tailored to the needs of specific groups.

\section{SUMMARY}

As computer-intensive campuses become more prevalent, microcomputers will be increasingly used as teaching tools in almost all academic disciplines; psychologists will inevitably be a part of the design and evaluation of these programs. Our research indicates that psychologists can facilitate the effective application of this technology by addressing several issues. Among these are finding ways to convert general positive attitudes about the value of microcomputers in education into beliefs that microcomputers will benefit individuals in specific ways, to understand the determinants of attitudes toward computers and computing, to develop effective training methods and procedures, to expand student and faculty views of computer applications, to measure the effectiveness of computers in curricula, to develop incentives and other means for encouraging curricular applications of computers, and to search for predictors of attitudes, proficiency, use, and satisfaction among different subgroups of students and faculty. 